Enabling team learning when members are prone to contentious communication: The role of team leader coaching (c) The Author(s) 2016

Reprints and permissions: sagepub.co.uk/journalsPermissions.nav DOI: I0.I|77/00|87267|5622673 hum.sagepub.com

\title{
John Schaubroeck
}

Michigan State University, USA

\section{Abraham Carmeli}

Tel Aviv University, Israel

\section{Sarena Bhatia}

Michigan State University, USA

\section{Etty Paz}

Western Galilee Academic College, Israel

\begin{abstract}
Members of teams are often prone to interpersonal communication patterns that can undermine the team's capacity to engage in self-learning processes that are critical to team adaptation and performance improvement. We argue that team leader coaching behaviors are critical to ensuring that team discussions that may foster learning new teamwork skills and strategies are unfettered by the tendency of two or more members to exhibit contentious interpersonal communications. We accordingly test a model in which team contentious communication moderates the mediated relationship of team leader coaching behaviors on team innovation effectiveness and team task performance. In a study of 82 work teams, team leader coaching behaviors exhibited indirect, positive relationships with both team innovation effectiveness and team task performance through team learning, but only among teams with an average or higher
\end{abstract}

\section{Corresponding author:}

John Schaubroeck, Department of Psychology, Michigan State University, East Lansing, MI 48824, USA.

Email: schaubroeck@bus.msu.edu; schaubroeck@Broad.msu.edu 
level of contentious interpersonal communication. We discuss theoretical and practical implications for the leadership of teams.

\section{Keywords}

contentious communication, group communication, team innovation, team leader coaching, team learning, team performance

As work teams have become more prevalent and vital to organizations, scholars and practitioners have become increasingly interested in how team processes influence important team outcomes such as innovation and performance (Burke et al., 2008; Shaw et al., 2011). Researchers have placed considerable emphasis on the benefits to team learning and adaptation that derive from the ability and willingness of members to share diverging perspectives about team tasks and priorities (Behfar et al., 2008). Yet, many teams may not reap these benefits when contentious patterns of interaction between two or more members impede collective learning. Such teams may face difficulties in adapting to change, improving their processes, and creating innovative products or services (Lovelace et al., 2001).

The potential for disruptive interpersonal communication in team discussions suggests an important role for team leaders. Team leaders can mitigate the extent to which existing frictions between particular team members impact the quality of team discussions, and they may thereby better ensure higher team functioning. Yet, although scholars have begun to appreciate the role of team leaders in facilitating group processes (Morgeson, 2005), the potential beneficial role that adept team leaders may play in teams prone to dysfunctional communication patterns has received only limited attention (Schippers et al., 2008). We advance a novel theoretical perspective by focusing on team leader coaching (TLC) (Carson et al., 2007; Edmondson 1999, 2003) and conceptually differentiating the context of team discussion that is vital to team learning from the interpersonal tendencies among members (i.e. levels of interpersonal contentious communication between members).

Edmondson and her colleague (Cannon and Edmondson, 2001; Edmondson, 1999; 2003 ) formulated the construct of TLC in terms of a relatively narrow set of behaviors. From their perspective, effective TLC involves initiating team discussions about how to improve team processes and learn new skills, actively facilitating these discussions, and being readily available for help and consultation about team and interpersonal issues. TLC may play an important role in enabling group learning in teams that struggle with contentious communication. Contentious communication refers to a pattern of unproductive interactions between two or more persons in which each tries to show he or she is right and insists the other is wrong (Lovelace et al., 2001). Without a team leader who insists the group meet and openly discuss issues that may promote learning, and who facilitates these discussions in ways that keep the team focused on learning, teams in which members have a propensity for contentious communication may fail to have the open and frank discussions about the team's interaction processes they require to learn from their experiences. Experiential team learning ('team learning,' hereafter) refers to 
'activities carried out by team members through which a team obtains and processes data that allow it to adapt and improve' (Edmondson, 1999: 353). Moreover, without a suitable mechanism for team learning, teams will not discover, develop and implement better ways to coordinate members' actions and to adapt quickly when environmental changes demand new approaches. Thus, we argue that TLC behaviors are critical for teams that are otherwise less able to engage in open and inclusive discussion. Overcoming barriers to team learning not only promotes team productivity as argued by Edmondson (1999), but doing so also enables teams to develop and implement novel products or processes (West, 2002).

We extend previous research on TLC, team learning and team task performance by developing a model in which TLC is particularly crucial for team learning when there is more potential for members' extant contentious communication patterns to disrupt group discussion. The favorable effects of TLC behaviors on team learning, in turn, promote team task performance and team innovation effectiveness. Thus, we argue that TLC will be more important in teams that exhibit patterns of contentious communication in the day-to-day interactions of at least some of their members. We present a test of this model of moderated mediation based on a sample of work teams that were temporally stable, such that the teams served as the work units of the team members.

\section{Theory and hypothesis development}

Maier (1950) and Maier and Solem (1952) reported on what were arguably the first prominent studies of group leadership. These classic studies demonstrated that practices in which formal group leaders engaged to facilitate discussion in ad hoc work groups were associated with more creative and effective solutions to particular task problems. Whereas these studies did not test mediation, the qualitative findings suggested that groups encouraged by the leader to exhibit more open interaction achieved better outcomes. Groups were especially successful when their leaders served as gatekeepers who encouraged inputs from members who held opinions that differed from the majority.

Since this seminal work of Maier and colleagues, conceptions of team leaders have moved away from considering their role as facilitators who buffer relationships between team states and team outcomes, and have instead focused largely on how broad composites of leader behaviors (e.g. transformational leadership) directly influence teams' learning, performance, or creative outcomes (e.g. Eisenbeiss et al., 2008). We draw from Maier and colleagues' less 'heroic' view of team leaders in suggesting that merely by being available to members for consultation, and initiating and facilitating team discussions, team leaders can prevent latent contentious communication patterns between two or more members from undermining the team's ability to learn and thereby improve its ability to function as a team.

We first review the role that TLC behaviors may play in promoting team learning. We then consider how such behaviors, which are similar to the 'democratic' behaviors Maier and colleagues emphasized as being most critical for group facilitation (Maier, 1950; Maier and Solem, 1952), are especially instrumental to team learning when interpersonal dynamics between members threaten to undermine team discussions. 


\section{Influences of team leader coaching (TLC) on team learning}

A team is unlikely to respond in a consistently adaptive manner to changing task demands unless it engages in a substantial amount of team learning (Argote, 1999). Team learning requires collaborative reflection about the team's experiences, with the aim to improve members' ability to collaborate by improving their patterns of interaction. Much of this learning centers on identifying and experimenting with ways members work together. Successful team learning may, for example, establish better approaches to performing a new collective task or to utilizing a new technology. Alternatively, members may improve their skills for coordinating team action in particular phases of projects in which the team has experienced difficulties (Edmondson, 2003).

Effective team learning involves raising doubts, seeking feedback, reflecting, and engaging in experimentation. Thus, it requires that members are willing and able to freely share their views, listen to one another, and demonstrate a willingness to reconsider their own views and integrate them with others (see Burke et al., 2008; Edmondson, 1999). Team learning is especially important for teams in which members engage a great deal of their time at work and which are stable in terms of membership. It is particularly advantageous in such situations because there is a higher potential return to the team's investments of time and effort into learning new skills and strategies (Katz, 1982).

The team leader often plays a substantial role in instigating and facilitating discussions that promote team learning. As suggested by Maier (1950), a group leader's primary role is to remove collective and interpersonal barriers to team members' interaction and thereby to aid the team in its progression toward greater collective self-regulation. Teams tend to learn collectively only when they perceive that the work context supports their taking the interpersonal risks that such learning requires (Burke et al., 2008; Edmondson, 1999). This function of the leader is not highly directive, because for a group to operate effectively as a team, the members themselves must take responsibility for team learning (Kozlowski, 1998; Maier, 1950).

As stated by Edmondson (2003: 124), TLC refers to 'any leader behaviours that explicitly invite and clarify the need for others' input or that seek to minimize power differences.'Within Edmondson's perspective (Cannon and Edmondson, 2001; Edmondson, 1999), the hallmarks of TLC are high accessibility for consultation, a propensity to initiate team meetings, and concerted efforts to instigate and facilitate open team discussions. Team leaders' initiations of team discussions provide a context wherein learning may occur, as members normally do not tend to initiate such meetings of their own accord (Burke et al., 2008). Facilitating these discussions in such a manner that all members freely share their knowledge and ideas and communicate in a collaborative fashion then becomes crucial to fostering learning. Edmondson (1999) reported that TLC was positively correlated with team members' aggregated perceptions of a supportive work climate for the team, team efficacy and team learning (cf. Cannon and Edmondson, 2001).

Based on the extant conceptual work and empirical findings concerning the relationship between TLC and team learning, we propose the following hypothesis:

Hypothesis 1: Team leader coaching (TLC) is positively related to team learning. 


\section{Moderating role of contentious communication}

Teams may be less likely to learn collectively when particular members are prone to engaging dysfunctional patterns of interpersonal communication that attempt to assert dominance over one or more other members, particularly when these patterns are on display and unfettered during team discussions that are oriented toward reflection and problem-solving. The construct of contentious communication derives from research on bilateral negotiations that investigated how the behavior of different parties led to more or less integrative (i.e. reflecting the collaboration of the parties) negotiation agreements. For example, Brett et al. (1998) assessed contentious communication by coding comments in which participants referred to norms, standards or fairness ('We must use my approach because we already used your ideas') or to power ('I will never agree to your idea'). They found that the other party normally reciprocated contentious comments, creating an ongoing state of contentious interaction between the parties that precluded integrative negotiation outcomes. Notably, a high average level of contentious communication in a group does not necessarily imply that all members maintain contentious communication patterns with one another. However, one or more contentious dyads can potentially create an atmosphere during discussion that prevents a productive discussion.

Maier (1950) observed that when group members' communications focus on interpersonal differences, members become less satisfied with one another and their frustration and tension lead them to argue and to avoid collaborative engagement. Members take strident and inflexible positions on group issues and more often misconstrue others' disagreement with their positions as personal attacks (Amason and Schweiger, 1994). Instead of welcoming others' initiatives, members who are prone to contentious interpersonal interactions view them as part of the 'tug-of-war' for power and control in the group (Brett et al., 1988: 441). When members observe others engage in contentious interpersonal interactions, either within or outside the context of team discussions, they may be less willing to participate in a team discussion that is oriented toward learning because they anticipate that speaking candidly about the group's interaction processes will ensnare them in similarly contentious interactions with those members. Thus, they may expect that their observations, suggestions or other initiatives will elicit combative reactions. In addition, members can become 'hooked' into other members' contentious patterns in such a way that they themselves contribute to the team missing an opportunity to learn through discussion.

Thus, effective TLC can be particularly critical for team learning when at least two members tend to engage in contentious interpersonal communications during the day-today activities of the group. A key part of an effective team leader's facilitation of team discussion is to ensure inclusive input from all members, and in doing so he or she must ensure that such contentious behavior does not undermine the discussion. To illustrate, suppose a team leader has initiated team discussions in an effort to take full account of the team's experiences, both favorable and unfavorable, in relation to a recent project. On each occasion, however, the same two members utilize this team meeting as an opportunity to assert dominance over one another. This leads some members to remain silent, either from fear of provoking these members or because the atmosphere created by the contentious exchanges weakens their desire to speak candidly and in the spirit of collaboration. Owing to their frustration with these episodes, some members may no longer participate in team discussions that consider how members work together. Such 
patterns of member demoralization are reflected in the findings of a number of studies that have linked relationship conflict in groups to lower group performance and creativity, and to lower member outcomes such as satisfaction (Behfar et al., 2008; De Dreu and Weingart, 2003; de Wit et al., 2012; Hülsheger et al., 2009).

Owing to their high accessibility to team members, team leaders who exhibit coaching behaviors are likely to be more aware of interpersonal differences within the team that may contribute to contentious interpersonal communications. They are also likely to have a more nuanced understanding of the relational dynamics within the team than are team leaders who do not engage in coaching behaviors. Such team leaders can therefore more readily identify the potential for a contentious communication pattern between two members to surface in a team meeting and potentially derail the discussion. This awareness helps the leader identify when it is necessary to intervene in team discussions in ways that prevent contentious communication among these members from surfacing, and if they do surface, redirect their attention to reflection, problem identification and problem-solving.

Contentious communication patterns are often activated by members' inability or lack of motivation to regulate emotions that arise from frustration and failure. Marks et al. (2001: 353) proposed that one role of team leaders is to engage in facilitating behaviors that regulate member emotions ('affect management') and to '... [establish] conditions that prevent, control, or guide team conflict before it occurs'. If contentious communication emerges during a team discussion, a team leader who engages in coaching may redirect and refocus the conversation. He or she might do so by using statements such as, 'The topic now is not about either of you individually, but rather with how the whole team can learn to better perform this task.' Thus, through coaching behaviors, the team leader can assert what Barsade and Gibson (1998) called normative control, which is a form of the general affect management role of team leaders (cf. Marks et al., 2001). Normative control occurs when members modify or constrain their expression of destructive negative emotions. Muting such emotions facilitates interaction and the free exchange of ideas. A team leader may further facilitate discussion by bringing potentially reticent members into the conversation (e.g. 'Deb, you seemed to have an idea about how we might do this. Can you share it with the team?'). Maier (1950: 167) deemed such 'democratic' team leader behaviors critical for team problem-solving. He suggested some principles of effective team leadership that have direct relevance for ensuring what we now call psychological safety (Kahn, 1990). These principles include: 'Protect individuals from criticism of other team members by interpreting all remarks in a favorable light'; 'Keep the discussion problem-centered, and see that no one is blamed or criticized by you'; and 'Do not hasten the discussion by capitalizing on the first good lead, or in any other way reflect your preferences.'

When contentious communication surfaces in team discussions, we expect that leaders who exhibit high TLC behavior will not only be physically present; through their inclusive behaviors they may tend to facilitate the discussion in such a way that such communications do not persist and undermine discussion quality. Thus, when certain members are prone to contentious interpersonal communications and opportunities arise in which candid discussion among all members of the team could promote team learning, TLC may often be the difference between a discussion with a favorable outcome and one that is derailed by tit-for-tat cycles of interpersonal blame and criticism. Conversely, in teams in which all members enjoy interpersonal relationships with little 
contentious communication, the role of TLC in facilitating discussion may be less critical. This rationale leads to the following interaction hypothesis:

Hypothesis 2: Contentious communication moderates the relationship between team leader coaching (TLC) and team learning, such that TLC is more strongly related to team learning among teams with high prevailing levels of contentious interpersonal communication.

\section{Conditional indirect relationships with team innovation effectiveness}

The ability to learn as a team is critical for teams to innovate effectively. As defined by Rogers, innovation is 'an idea, practice, or object that is perceived as new by an individual or other unit of adoption' (Rogers, 2003: 12). Team innovation effectiveness refers to the team's success in developing and applying novel approaches and solutions (Van de Ven and Chu, 1989). Teams that innovate effectively originate new products and/or develop processes to identify solutions and to collaborate toward putting new ideas into practice. For teams to develop their own processes, solutions and products, members must be able to identify and evaluate problems and opportunities in candid discussions through which all members can integrate their individual knowledge. The team must also be willing to experiment and take risks in implementing new ideas (Edmondson, 1999). This is less likely when contentious interpersonal patterns among certain members surface during open team discussions and disrupt the potential for members to integrate their perspectives in ways that generate team learning.

Team learning enables team members to understand how they can best pattern their interactions to behave collaboratively. It also facilitates knowledge integration because it helps members mentally catalogue where knowledge resides in the team. This, in turn, enables members to develop schemas about how to leverage individual members' expertise in particular tasks or projects to achieve innovation. However, if there is a tendency for fractious interpersonal communication patterns to surface during team discussions, members may find that their motives and intentions are called into question. Novel or risky task-related suggestions may be criticized, reducing members' willingness to share their ideas and observations openly (Shaw et al., 2011). Thus, when contentious communication patterns are permitted to arise unfettered during team meetings, lines of discussion that could potentially lead to innovative insights are less likely to come to fruition.

In the preceding section, we noted how facilitation by team leaders can shape team discussions in ways that avoid the surfacing of contentious communication patterns. By focusing the team's attention on task objectives and serving an effective gate-keeping role, a team leader can ensure that contentious communication tendencies that may exist in the day-to-day interactions of some team members do not impede the team's diagnosis and solution-finding strategies. The team can then integrate knowledge in ways that exploit opportunities to innovate. We therefore propose that team leaders' coaching behaviors influence team innovation performance through TL when the average level of contentious communication perceived by the team is high:

Hypothesis 3: Contentious communication moderates the mediated relationship between team leader coaching (TLC) and team innovation effectiveness; there are 
stronger indirect relationships between TLC and team innovation effectiveness through team learning among teams in which some members have established contentious interpersonal communications patterns.

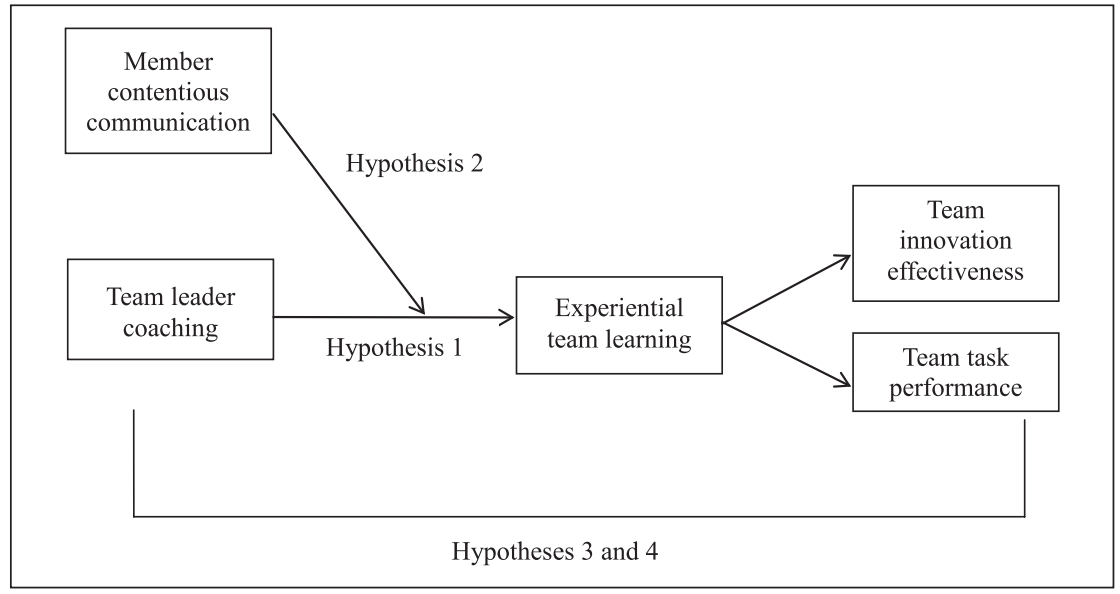

Figure I. Hypothesized model.

\section{Team learning (TL) and team task performance}

Team learning is also vital for members to find new ways to perform their routine duties more effectively (Argote, 1999; Edmondson, 1999). Team task performance refers to how well the team meets its established goals. High team performance consists of producing team outputs on time, within budget and with high quality irrespective of changing demands. Unlike high team innovation effectiveness, the team's processes or products are not necessarily novel to the team or organization. The relationship between extant member contentious communication and team task performance through team learning nevertheless derives from the same basic mechanism that links CC to TIE. As we have argued, effective TLC may prevent contentious communication propensities of particular members from surfacing during team discussions and undermining team learning. Team learning, in turn, enhances the team's ability to perform its technical duties by adapting quickly to changing task demands (Argote, 1999). This reasoning suggests that TLC has a particularly advantageous influence on team task performance among teams who have at least some members who are prone to contentious interpersonal communication:

Hypothesis 4: Contentious communication moderates the mediated relationship between team leader coaching (TLC) and team task performance; there are stronger indirect relationships between TLC and team task performance through team learning among teams in which some members have established contentious interpersonal communications patterns. 
Table I. Means, standard deviations, correlations and alpha reliabilities of study variables.

\begin{tabular}{llllllllll}
\hline & Mean & SD & I & 2 & 3 & 4 & 5 & 6 \\
\hline I. Team size & 4.66 & 1.17 & - & & & & & \\
2. Contentious communication & 2.19 & 0.70 & .02 & $(.90)$ & & & & \\
3. Team leader coaching (TLC) & 4.26 & 0.51 & .08 & $-.28^{* * *}$ & $(.79)$ & & & \\
4. Team learning & 3.78 & 0.39 & -.05 & $-.29^{* *}$ & $.54^{* * * *}$ & $(.72)$ & & \\
5. Team innovation effectiveness & 3.96 & 0.66 & -.06 & -.03 & .20 & $.33^{* *}$ & $(.85)$ & \\
6. Team task performance & 3.94 & 0.64 & .07 & $-.24^{*}$ & $.39^{* * * * *}$ & $.49^{* * * *}$ & $.45^{* * \alpha *}$ & $(.89)$ \\
\hline
\end{tabular}

$N=82$ teams. $S D=$ standard deviation.

${ }^{*} p<.05,{ }^{* *} p<.01$, ${ }^{* * * * *} p<.001$.

Figure 1 shows the overall framework that encompasses the four hypotheses.

\section{Method}

\section{Sample and data collection}

We collected data from 338 employees representing work teams in 10 service organizations in Israel. These included four information technology companies, a midsize hospital, two financial institutions, a higher educational institution and a power company. These teams were the work units of the employees. Data were collected in two waves. First, during participants' work time we distributed and collected a questionnaire from team members. This administration excluded the team leader, who in each case was the formal leader of the unit and did not perform the same tasks as team members. Six weeks later, we administered a survey to the team leaders, seeking their ratings of team innovation effectiveness and team task performance. As we sought to recruit 150 teams and obtained complete data from 82 teams, the participation rate was $54.7 \%$.

\section{Measures}

We followed Brislin et al.'s (1973) procedures for survey translations across different languages. Table 1 shows Cronbach's alpha reliabilities for the measures. All measurement items used a five-point scale ranging from 1 ('not at all') to 5 ('to a very large extent'). Members of each team (not including the leader) reported on TLC, team learning and contentious communication, and team leaders completed items regarding team size, team task performance and team innovation effectiveness.

Team innovation effectiveness. We adapted the measure of team innovation effectiveness from the 'perceived innovation effectiveness' subscale of the Minnesota Innovation Survey (Van de Ven and Chu, 1989). We modified the original items by asking team leaders to evaluate the team as a whole and in reference to their average effectiveness rather than to the 'individuals involved with' a specific innovation (Van de Ven and Chu, 1989: 94). We did 
not use one of the original five items that referred to the technical performance of the team. That particular question was connected to a stem that referenced a specific innovation.

Team task performance. We adapted Hoegl and Gemuenden's (2001) 10-item measure of team performance effectiveness to assess team task performance. We substituted the word 'team' for 'project,' and we referred to the team's average performance rather than to its performance on a specific project. Sample items include, 'Going by its results, this team can be regarded as successful' and 'From the company's perspective, this team achieves its goals.'

Team learning and team leader coaching (TLC). We used instruments developed and reported by Edmondson (1999) to measure both team learning and TLC. The team learning measure contains seven items (e.g. 'People in this team often speak up to test assumptions about issues under discussion). The TLC index includes three items that begin with the stem, 'The team leader ...' ('... initiates meetings to discuss the team's progress'; ‘... is available for consultation on problems'; and '... is an ongoing "presence" in this, team - someone is readily available').

Team contentious communication contentious communication. We adapted Lovelace et al.'s (2001) six-item measure to assess team contentious communication. Their items asked team members to recall a particular episode in which there was a disagreement in the team and to state the extent to which the members exhibited particular behaviors in that situation. We modified these items by asking members to report on the extent to which particular communications characterize the interpersonal communications between members in interactions in which they disagreed about how to proceed. Participants reported the extent to which the statements used by Lovelace et al. (2001; e.g. 'You're not listening' or 'Why are you being so stubborn?') were characteristic of members' communications in such situations.

\section{Results}

\section{Preliminary analyses and correlations}

We used the LISREL 8.80 computer program (Jöreskog and Sörbom, 2006) to test the measurement model. We first conducted a confirmatory factor analysis to test a congeneric measurement model in which the items for all measures reported by team members (i.e. contentious communication, TLC, team learning) were specified to load onto their own unique latent variable. This analysis used the individual level sample $(N=338)$. This model provided a good fit to the data $\left(\chi_{(101)}^{2}=330.91\right.$, Root Mean Square Error of Approximation $(\mathrm{RMSEA})=.08$, Normed Fit Index $(\mathrm{NFI})=.94$, Comparative Fit Index $[\mathrm{CFI}]=.96)$. We also tested an alternative one-factor measurement model by fixing each of the factor correlations to a value of 1.0. The fit of this model was substantially worse $\left(\chi_{(104)}^{2}=776.99\left(\Delta \quad \chi_{(3)}^{2}=446.08, p<.001\right), \mathrm{RMSEA}=.14, \mathrm{NFI}=.88, \mathrm{CFI}=.90\right)$. These findings together support analyzing these measures as separate analysis constructs.

We first sought to determine whether aggregating individual means to group level, as for composition constructs, was justified by high levels of within-group agreement. The mean $r_{\mathrm{WG}(j)}$ (James et al., 1984) statistic was higher than the conventional threshold of .70 
Table 2. Regression analyses testing Hypotheses I and 2.

\begin{tabular}{|c|c|c|c|c|c|c|}
\hline & \multicolumn{2}{|c|}{ Team learning } & \multicolumn{2}{|c|}{ Team learning } & \multicolumn{2}{|c|}{ Team learning } \\
\hline & Coeff. & SE & Coeff. & SE & Coeff. & SE \\
\hline Constant & $3.78^{* k}$ & .04 & $3.78^{* *}$ & .04 & $3.80^{* *}$ & .04 \\
\hline \multicolumn{7}{|l|}{ Independent variables } \\
\hline Team leader coaching (TLC) & $.42^{* *}$ & .07 & $.38^{* *}$ & .08 & $.37^{* *}$ & .07 \\
\hline Contentious communication (CC) & & & -.09 & .06 & -.09 & .05 \\
\hline$T L C \times C C$ & & & & & $.26^{*}$ & .11 \\
\hline$\Delta R^{2}$ & & & .021 & & $.043^{*}$ & \\
\hline Total $R^{2}$ & $.292^{* *}$ & & $.313^{* *}$ & & $.357^{* *}$ & \\
\hline
\end{tabular}

$N=82$ teams. Coeff. $=$ coefficient; $\mathrm{SE}=$ standard error;

${ }^{*} p<.05,{ }^{* * * *} p<.001$.

for each of the analysis variables. This value was exceeded for each of the predictors. Because the teams represented 10 different organizations, we examined whether accounting for the nesting within these organizations may influence the results. We first examined the magnitude of non-independence as indexed by $\mathrm{ICC}_{(1)}$ using hierarchical linear modeling (HLM 7; Raudenbush et al., 2011). The $\mathrm{ICC}_{(1)}$ values were negligible $(<.01)$ for all three outcome variables (team task performance, team innovation effectiveness, and team learning) indicating that the between-group (vs between-organization) component accounted for more than $99.9 \%$ of the variance in each outcome in a two-level null model. We therefore tested the hypotheses using ordinary least squares estimation.

Table 1 shows the correlations among the analysis variables. Notably, the correlation between team innovation effectiveness and team task performance is moderate $(r=.45)$, indicating that assessments of the two outcomes are empirically distinct. The correlation between contentious communication and team innovation effectiveness is negligible, whereas contentious communication has a significant correlation with team task performance. TLC and team learning are significantly correlated with both outcome variables, with the exception that the correlation between TLC and team innovation effectiveness is not significant $(r=.20, p<.07)$. Team size is not significantly correlated with any of the analysis variables. We therefore did not include team size as a control variable in testing the hypotheses.

\section{Tests of hypotheses}

The results for regression analyses testing Hypotheses 1 and 2 are shown in Table 2 . Hypothesis 1, which predicts that TLC is positively related to team learning, was supported $(p<.001)$. Hypothesis 2 predicts that contentious communication moderates the relationship between TLC and team learning. TLC and contentious communication were each mean centered prior to computing the interaction variable. As shown in Table 2, the interaction was significantly related to team learning $\left(R^{2}=.043 ; F(1,78)\right.$ $=5.23, p<.05)$. Figure 2 depicts the pattern of this interaction, with values plotted at $+/-1$ SD from the mean of contentious communication. As hypothesized, TLC had a stronger positive relationship with team learning when contentious communication 


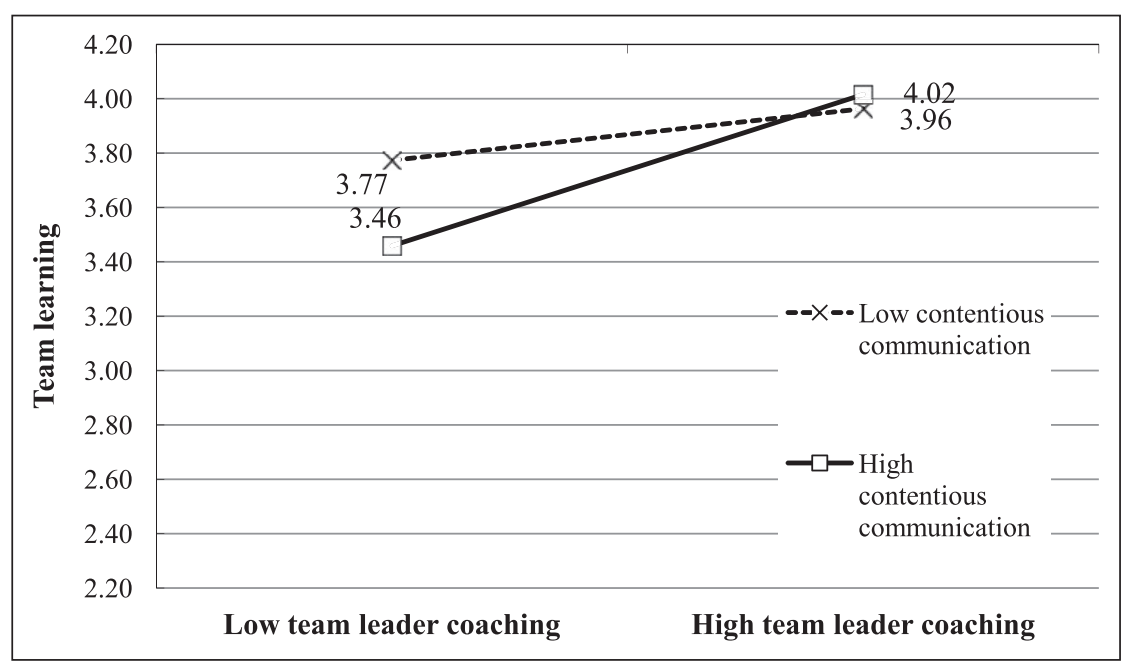

Figure 2. Influence of TLC on team learning as moderated by CC (Hypothesis I). Simple slope $t$-statistics are $t=1.91(p<.06)$ for low team learning CC and $t=6.34(p<.00 \mathrm{I})$ for high CC.

was high $(p<.001)$ compared with when it was low. For low contentious communication, the simple effect of TLC indicates a positive trend, but it was not statistically significant $(t=1.91, p<.06)$. Team learning levels were equally high among teams with leaders who exhibited a propensity for coaching, regardless of the level of contentious communication. Thus, the key difference lies in the relatively low levels of team learning reported by teams with high prevailing levels of contentious communication who also reported low TLC.

Given that the interaction was significant in predicting team learning, we proceeded to test Hypotheses 3 and 4 using the MODMED statistical program (Preacher et al., 2007). Hypothesis 3 concerns the indirect relationship between TLC and team innovation effectiveness through team learning as conditioned by contentious communication. The normal theory estimate (Sobel test) of the indirect effect for teams with low contentious communication was not significant, and the confidence interval for the bootstrap estimate of the indirect effect ( $a b$ ) included zero (see Table 3). When contentious communication was high or at its mean level, however, the Sobel tests were statistically significant, and the bootstrap confidence intervals for the indirect effects excluded zero with 95\% confidence. These results support Hypothesis 3 .

Hypothesis 4 predicts the same pattern of moderated mediation when team task performance is the outcome variable. As shown in Table 3, neither the Sobel test nor the 95\% bootstrap confidence interval indicated a significant indirect effect when contentious communication was low. When contentious communication was high or at its mean level, both the Sobel test and the bootstrap confidence interval supported a statistically significant indirect effect. Hypothesis 4 is therefore supported. 
Table 3. Conditional indirect effects of team leader coaching on team innovation effectiveness and team task performance through team learning (Hypotheses 3 and 4).

\begin{tabular}{|c|c|c|c|c|c|}
\hline $\begin{array}{l}\text { Independent } \\
\text { variable }\end{array}$ & $\begin{array}{l}\text { Dependent } \\
\text { variable }\end{array}$ & Mediator & Moderator ${ }^{\mathrm{a}}$ & $\begin{array}{l}\text { Normal theory } \\
\text { indirect effect (SE) }\end{array}$ & $\begin{array}{l}95 \% \\
\text { bootstrap Cl }\end{array}$ \\
\hline \multirow[t]{3}{*}{ TLC } & $\begin{array}{l}\text { Team } \\
\text { innovation } \\
\text { effectiveness }\end{array}$ & $\begin{array}{l}\text { Team } \\
\text { learning }\end{array}$ & Low, -I SD & . II (.08) & $(-.01, .08)$ \\
\hline & & & Mean & $.22 *(.09)$ & $(.06, .43)$ \\
\hline & & & High, +I SD & $.33 * *(.14)$ & $(.06, .65)$ \\
\hline \multirow[t]{3}{*}{ TLC } & $\begin{array}{l}\text { Team task } \\
\text { performance }\end{array}$ & $\begin{array}{l}\text { Team } \\
\text { learning }\end{array}$ & Low, -I SD & $.11(.08)$ & $(-.01, .29)$ \\
\hline & & & Mean & $.23 *(.09)$ & $(.06, .45)$ \\
\hline & & & High, + I SD & $.33 * *(.13)$ & $(.07, .68)$ \\
\hline
\end{tabular}

${ }^{*} p<.05, * * p<.01$.

aModerator = contentious communication.

$\mathrm{Cl}=$ confidence interval; $\mathrm{SD}=$ standard deviation;

TLC = team leader coaching.

\section{Supplementary analyses}

Using PROCESS (Hayes, 2012), we examined the simple mediated effects of TLC on the outcome variables through TLC. The indirect effects were positive and significant for both team task performance (bootstrap coefficient $=.24(\mathrm{SE}=.11), 95 \% \mathrm{CI}=[.07, .49])$ and team innovation effectiveness (bootstrap coefficient $=.21(\mathrm{SE}=.10), 95 \% \mathrm{CI}=[.06, .44])$.

Although our theoretical model does not specify a role for TLC as an antecedent of contentious communication, we sought to determine if specifying such a parameter would affect the interaction between TLC and contentious communication in predicting team learning. In their description of the various models that can be tested using their MODMED program, the first model defined by Preacher et al. (2007) specifies the same variable $(X)$ as both the antecedent of a predictor variable $(\mathrm{M})$ and a moderator of its influences on a third variable $(Y)$. In testing this model, the interaction of TLC and contentious communication in predicting team learning remained statistically significant $(p<.05)$. The results also showed that the added relationship between TLC and contentious communication was significant $(b=-.38(\mathrm{SE}=.15), t=-2.61, p<.01)$. However, using PROCESS, we tested an alternative model in which TLC is indirectly related to team learning through contentious communication. This model was not supported (bootstrap coefficient $=.03(\mathrm{SE}=.03), 95 \% \mathrm{CI}=[-.01, .12])$. This is consistent with the lack of relationship between contentious communication and team learning when TLC is in the equation (Table 2). In addition, with contentious communication specified as the mediating variable, we observed no indirect effect of TLC on team task performance (bootstrap coefficient $=.05(\mathrm{SE}=.04), 95 \% \mathrm{CI}=[-.01, .17])$ or team innovation effectiveness (bootstrap coefficient $=-.01(\mathrm{SE}=.05), 95 \% \mathrm{CI}=[-.10, .08])$. 


\section{Discussion}

In this article, we have argued that TLC has a particularly favorable influence on team outcomes when at least some team members are predisposed to engage in contentious interpersonal communications. Dysfunctional communication patterns have the potential to inhibit team learning if they are not discouraged from intruding upon team discussions. Thus, the presence of these tendencies provides greater scope for TLC to promote team learning. Our study found that whereas TLC had a generally favorable influence on team learning (Hypothesis 1), this connection was stronger among teams who had more often witnessed members engaging in contentious communication (Hypothesis 2). This produced in such teams more favorable indirect relationships between TLC and two team outcomes, namely innovation effectiveness and task performance, as compared with teams with low contentious communication (Hypotheses 3 and 4). These indirect relationships were equally strong at both high and average levels of contentious communication.

\section{Theoretical and practical implications}

Despite the benefits that develop over time from creating teams to coordinate individual effort (Ancona and Chong, 1996), all teams experience interpersonal misunderstandings and disagreements at times. A relatively stable state of contentious communication exists when interpersonal differences among certain members dispose them to a cycle of petty bickering and one-upmanship. Our study emphasizes the potential role of contentious communication in undermining team learning, team innovation effectiveness and team task performance. The primary contribution of this study concerns the moderating influence of team CC on the relationship between leader coaching behavior and team outcomes. Previous research suggests formal leaders should play a key role in diagnosing and managing conflictual dynamics in teams (De Dreu and Weingart, 2003). We argued that team leaders can play a pivotal role by ensuring that such dynamics do not undermine the discussions that are essential for team learning. Notably, the mean level of contentious communication was fairly low $(M=2.19, \mathrm{SD}=.70)$, and yet the indirect effects of TLC were equally significant for both outcomes (team innovation effectiveness and team task performance) at this level and at one standard deviation above the mean. This indicates that even a small propensity for contentious communication has the potential to reduce teams' ability to learn from experience if a team lacks a leader who exhibits coaching behaviors.

Our study focused on a specific pattern of team leader behavior, TLC, which helps to prevent contentious communication from prevailing during team discussions. Thus, the study identifies a context in which TLC behaviors are most needed for teams to perform and innovate successfully. Because open and reflective discussions that involve all members are not likely to occur outside of the context of team meetings, little team learning is likely to occur in a team that lacks a leader who engages in coaching behaviors. Yet, initiating such meetings does not guarantee their success in promoting team learning. Without the leader's further engagement in team coaching by facilitating discussion in these meetings, pre-existing contentious communication propensities can surface repeatedly, ultimately undermining the potential for the team to learn how to improve its 
functioning in ways that aid its performance and capacity to innovate. TLC facilitates team interaction by helping members focus on better ways to work as a team instead of on interpersonal differences and rivalries. Team leaders thus play an especially vital role in teams where open expression of task-focused and change-focused ideas and observations would be inhibited without active process facilitation.

To overcome such threats to team discussions, team leaders must use 'soft' influence in ways that permit experimentation, interpersonal feedback seeking, and deliberating about task problems and strategies as a team, and avoid assigning blame for performance miscues or for the disagreements themselves. For example, a team leader would be engaging in useful coaching when he or she initiates a team meeting to deliver feedback about member interaction processes, and then introduces the feedback in a way that deemphasizes the role of particular individuals. If the leader were to personalize the responsibility for errors, valuable corrective information could provoke individual defensiveness or cue certain members to blame a person with whom they have previously established a contentious communication pattern. Another useful practice for team leaders is to engage in gatekeeping behaviors that encourage quieter members to elaborate about ideas they had expressed at other times, or asking such members pointed questions in an effort to draw them out.

We speculate that skilled and trusted team leaders might also contribute to resolving the underlying issues that create contentious communication so that contentious communication may no longer prevail. When team leaders are effective in facilitating team decision-making and learning, members' positive experiences of working together are likely to provide a foundation for them to resolve their interpersonal disputes (Fay et al., 2006). In addition, team leaders can make their presence felt outside of team discussions in ways that support healing of rifts between members. When noticing members engaged in contentious communication, team leaders can note ways the parties could frame their discussion in a more constructive light. This may further aid team learning, as improved communications between these parties may encourage them to engage more cooperatively in team discussions. Team leaders who exhibit supportive coaching behaviors may also be less likely to be themselves prone to contentious communication when interacting with subordinates. Moreover, a more inclusive and accessible team leader is likely to possess interpersonal skills and a temperament that may serve as a role model for other team members to engage civilly with one another.

Our supplementary analyses demonstrated that the interaction effect on team learning was still significant when TLC was specified as an antecedent of contentious communication. Yet, we believe there are limits to which TLC may be expected to reduce the overall level of contentious communication among team members. Substantial effects of the team leader on the interpersonal climate of a group would imply influences that are more potent than may be expected from the TLC construct proffered by Edmondson (1999, 2003). Nevertheless, a potential separate role of TLC in reducing the average level of contentious communication within a work unit warrants future research.

A direct practical implication of our findings is that formal team leaders must take a more active role and engage coaching behaviors when a pattern of contentious communication emerges among members in a team discussion. Team leaders can help their teams perform better by initiating team meetings that aim to promote team learning, and 
then facilitating such meetings in ways that do not permit contentious communication patterns of certain members from undermining the effort. Organizations could also seek to place leaders who exhibit effective coaching behaviors into positions as leaders of teams in which contentious communication patterns already prevail. It is also important to note, however, that the behaviors associated with TLC should not be difficult to teach new or existing team leaders. Organizations can train leaders to be more effective in these coaching behaviors. Such training may be more effective for organizations that provide incentives for individuals to succeed in managing difficult teams.

\section{Limitations and future research directions}

Owing to our survey-based approach, we were unable to demonstrate causality among the variables or explore how contentious communication patterns and collaboration develop in teams. Bracketing patterns of communication in teams may reveal that episodes of collaborative communication reduce the likelihood that $\mathrm{CC}$ will interfere with short-term outcomes, irrespective of the average levels of contentious communication in these teams over a more substantial period. Longitudinal approaches such as latent growth modeling could also determine if recurring episodes in which team leaders are effective in promoting team learning, despite a pre-existing pattern of interpersonally contentiousness communication, aid in resolving the issues that precipitated these patterns.

As with nearly all studies, the generalizability of the findings is potentially subject to numerous boundary variables. One potential boundary condition is the high temporal stability and full-time nature of the teams we studied. In such teams, investment in team learning is especially important as it benefits future interactions on a broader range of team tasks than it may for short-term teams. In temporally stable teams, members develop patterns of relationship outside of the context of the team discussions that can either contribute to or impede team learning. Future research may seek to determine if these findings generalize to temporary teams, or to more permanent teams with which members are not engaged full-time.

Although team leaders who were rated high in coaching are more likely to initiate team meetings, some may be more effective than others in facilitating team meetings in ways that prevented contentious communication patterns from undermining discussion and in eliciting, guiding and synthesizing member discussion in ways that promoted team learning. Thus, it would be useful for future research to measure TLC in a more granular fashion that explicitly includes reference to affect and conflict management behaviors.

Future studies could also extend our research by examining whether there are substitutes for TLC in teams with high prevailing levels of contentious communication. For example, when teams members' roles are more structured in terms of who has power under different circumstances (i.e. high vertical specialization), contentious communication might have a weaker influence on team task performance (see Bunderson and Boumgarden, 2010). In addition, research on team innovation and creativity in project teams suggests that the stage of a team's development may influence the potential benefits of particular team leader behaviors (Farh et al., 2010). Future studies might profitably examine stages in team development in which TLC is more or less effective in promoting team learning and innovation. 
As suggested by a reviewer, TLC influences may be moderated by other forms of poor interpersonal communication in teams, such as ignoring others' inputs. Ignoring a particular person may be part of many interpersonal histories of contentious communication, and a failure to listen may sustain these contentious communication cycles. Yet, marginalizing others by ignoring their input can limit learning from team discussions even among teams that tend to be less prone to contentious communication. Effective TLC ensures that members are not ignored, making them more likely to provide inputs that are useful for team learning. Futures studies may therefore also consider the roles of dismissive behaviors that undermine discussion quality and thereby deter team learning.

\section{Conclusion}

Our study suggests that TLC behaviors can be particularly effective in promoting team learning in teams with high mean levels of contentious interpersonal communication. Leaders who engage in coaching behaviors initiate team discussions and facilitate such discussions in ways that create an open atmosphere in which the inquiries and challenges that are necessary ingredients of team learning are encouraged rather than met with derision. By enabling team learning in contexts in which there is potential for some members to focus on other members' shortcomings and assign blame, such team leaders can enhance the likelihood that the team can learn to improve and adapt to change in ways that foster innovation and task performance.

\section{Funding}

This study was supported by the Henry Crown Institute of Business Research.

\section{References}

Amason AC and Schweiger DM (1994) Resolving the paradox of conflict, strategic decision making, and organizational performance. International Journal of Conflict Management 5(3): 239-253.

Ancona DG and Chong C (1996) Entrainment: Pace, cycle, and rhythm in organizational behavior. Research in Organizational Behavior 8: 251-284.

Argote L (1999) Organizational Learning: Creating, Retaining, and Transferring Knowledge. Norwell, MA: Kluwer.

Barsade SG and Gibson DE (1998) Group emotion: A view from top and bottom. In: Gruenfeld DH (ed.) Research on Managing Groups and Teams. Stamford, CT: JAI Press, 81-102.

Behfar KJ, Peterson RS, Mannix EA and Trochim WMK (2008) The critical role of conflict resolution in teams: A close look at the links between conflict type, conflict management strategies, and team outcomes. Journal of Applied Psychology 93(1): 170-188.

Brett JM, Shapiro DL and Lytle AL (1998) Breaking the bonds of reciprocity in negotiations. Academy of Management Journal 41(4): 410-424.

Brislin R, Lonner W and Thorndike R (1973) Cross-cultural Research Methods. New York: Wiley.

Bunderson JS and Boumgarden P (2010) Structure and learning in self-managed teams: Why 'bureaucratic' teams can be better learners. Organization Science 21(3): 609-624.

Burke CS, Salas E and Diaz D (2008) The role of team learning in facilitating team adaptation within complex environments: Tools and strategies. In: Sessa VI and London M (eds) Work Group 
Learning: Understanding, Improving \& Assessing How Groups Learn in Organizations. New York: Lawrence Erlbaum Associates, 217-241.

Cannon MD and Edmondson AC (2001) Confronting failure: Antecedents and consequences of shared beliefs about failure in organizational work groups. Journal of Organizational Behavior 22(2): 161-177.

Carson JB, Tesluk PE and Marrone JA (2007) Shared leadership in teams: An investigation of antecedent conditions and performance. Academy of Management Journal 50(5): 1217-1234.

De Dreu CKW and Weingart LR (2003) Task versus relationship conflict, team performance, and team member satisfaction: A meta-analysis. Journal of Applied Psychology 88(4): 741-749.

de Wit FR, Greer LL and Jehn KA (2012) The paradox of intragroup conflict: A meta-analysis. Journal of Applied Psychology 97(2): 360-390.

Edmondson AC (1999) Psychological safety and learning behavior in work teams. Administrative Science Quarterly 44(2): 350-383.

Edmondson AC (2003) Speaking up in the operating room: How team leaders promote learning in interdisciplinary action teams. Journal of Management Studies 40(6): 1419-1453.

Eisenbeiss SA, van Knippenberg D and Boerner S (2008) Transformational leadership and team innovation: Integrating team climate principles. Journal of Applied Psychology 93(6): 1438-1446.

Farh JL, Lee C and Farh CI (2010) Task conflict and team creativity: A question of how much and when. Journal of Applied Psychology 95(6): 1173.

Fay D, Borrill C, Amir Z, et al. (2006) Getting the most out of multidisciplinary teams: A multisample study of team innovation in health care. Journal of Occupational and Organizational Psychology 79(4): 553-567.

Hayes AF (2012) PROCESS: A versatile computational tool for observed variable moderation, mediation, and conditional process modeling. Available at: http://www.afhayes.com (accessed 30 January 2016).

Hoegl M and Gemuenden HG (2001) Teamwork quality and the success of innovative projects: A theoretical concept and empirical evidence. Organization Science 12(4): 435-449.

Hülsheger UR, Anderson N and Salgado JF (2009) Team-level predictors of innovation at work: A comprehensive meta-analysis spanning three decades of research. Journal of Applied Psychology 94(5): 1128-1145.

James LR, Demaree RG and Wolf G (1984) Estimating within-group interrater reliability with and without response bias. Journal of Applied Psychology 69(1): 85-98.

Jöreskog KG and Sörbom D (2006) LISREL 8.80 for Windows [Computer software]. Lincolnwood, IL: Scientific Software International.

Kahn WA (1990) Psychological conditions of personal engagement and disengagement at work. Academy of Management Journal 33: 692-724.

Katz R (1982) The effects of group longevity on project communication and performance. Administrative Science Quarterly 22(1): 81-104.

Kozlowski SWJ (1998) Training and developing adaptive teams: Theory, principles, and research. In: Cannon-Bowers A and Salas E (eds) Decision Making Under Stress: Implications for Training and Simulation. Washington, DC: APA Books, 115-153.

Lovelace K, Shapiro DL and Weingart LR (2001) Maximizing cross-functional new product teams' innovativeness and constraint adherence: A conflict communications perspective. Academy of Management Journal 44(4): 779-793.

Maier NRF (1950) The quality of group decisions as influenced by the discussion leader. Human Relations 3: 155-174. 
Maier NRF and Solem AR (1952) The contribution of a discussion leader to the quality of group thinking: The effective use of minority opinions. Human Relations 5: 277-288.

Marks MA, Mathieu JE and Zaccaro SJ (2001) A temporally based framework and taxonomy of team processes. Academy of Management Review 26(3): 356-376.

Morgeson FP (2005) The external leadership of self-managing teams: Intervening in the context of novel and disruptive events. Journal of Applied Psychology 90(3): 497-508.

Preacher KJ, Rucker DD and Hayes AF (2007) Assessing moderated mediation hypotheses: Theory, methods, and prescriptions. Multivariate Behavioral Research 42(1): 185-227.

Raudenbush SW, Bryk AS, Cheong YF, et al. (2011) HLM 7: Hierarchical Linear and Non-linear Modeling. Chicago: Scientific Software International.

Rogers EM (2003) Diffusion of Innovation (5th edn). New York: Free Press.

Schippers MC, Den Hartog DN, Koopman PL and van Knippenberg D (2008) The role of transformational leadership in enhancing team reflexivity. Human Relations 61(11): 1593-1616.

Shaw JD, Zhu J, Duffy MK, Scott KL, et al. (2011) A contingency model of conflict and team effectiveness. Journal of Applied Psychology 96(2): 391-400.

Van de Ven AH and Chu Y (1989) A psychometric assessment of the Minnesota Innovation Survey. In: Van de Ven AH, Angle HL and Poole MS (eds) Research on the Management of Innovation: The Minnesota Studies. New York: Harper \& Row, 55-103.

West MA (2002) Sparkling fountains or stagnant ponds: An integrative model of creativity and innovation implementation in work groups. Applied Psychology 51(3): 355-387.

John M Schaubroeck is currently the John A Hannah Distinguished Professor of Psychology and Management at Michigan State University, USA. He received his PhD from the Krannert Graduate School of Management at Purdue University, USA. His research interests relate primarily to leadership and employee well-being. [Email: schaubroeck@Broad.msu.edu]

Abraham Carmeli serves on the faculty of Tel Aviv University, Israel, and University of Birmingham, UK. He received his $\mathrm{PhD}$ from the University of Haifa. His current research interests include CEO leadership and top management teams, positive relational dynamics, learning from failure, and creativity and innovation in the workplace. [Email: avic@post.tau.ac.il]

Sarena Bhatia is a doctoral student in the Organizational Psychology program at Michigan State University, USA. Her research interests are in personnel selection and assessment, and training. She often uses applied problems and projects as an inspiration for her research, and has worked with almost a dozen organizations in an effort to understand how to best select and develop people in a variety of industries. She is currently contributing to a book on career interests as well as several papers on personality assessments. [Email: sbhatia@msu.edu]

Etty Paz is a faculty member at the management school of Western Galilee Academic College in Acre (a branch of Bar Ilan University), Israel. Dr Paz specializes in strategic human resource management and conflict resolution in organizations. She received her PhD from Bar Ilan University in 2007. She is the owner of one of the pioneering organizational development and management consultancy firms in Israel. Dr Paz was in charge of both practicum and mentoring MBA programs at PAC (Peres Academic Center) in Rehovot for five years (2009-2014). [Email: Etip@wgalil.ac.il] 